\title{
A novel device for hands-free positioning and adjustment of the surgical microscope
}

\author{
Technical note
}

\author{
David I. Pitskhelauri, M.D., Ph.D., ${ }^{1}$ Alexander N. Konovalov, M.D., Ph.D., ${ }^{1}$ \\ Georgy A. Shekutev, M.D., Ph.D., ${ }^{2}$ Nikolay B. Rojnin, Ph.D., ${ }^{3}$ \\ Igor A. Kachkov, M.D., Ph.D., ${ }^{4}$ DMitry Y. Samborskiy, ${ }^{1}$ Alexander Z. Sanikidze, M.D., ${ }^{1}$ \\ and DMitry N. KopacheV, M.D. ${ }^{1}$
}

${ }^{1}$ Neurooncology and ${ }^{2}$ Neurophysiology, Burdenko Neurosurgery Institute; ${ }^{3}$ Moscow Aviation Institute; and ${ }^{4}$ Neurooncology, Vladimirsky Moscow Regional Research Clinical Institute, Moscow, Russia

\begin{abstract}
The authors have developed a novel device, which they have named Mari, that allows hands-free utilization of the surgical microscope. The device is attached to the eyepieces of a multifunction counterweight-balanced surgical microscope and consists of a metallic holder with supportive plates that facilitate interaction between the device and surgeon's head. On the holder are installed 1) an electric switch, which allows the surgeon to release the microscope's magnetic clutches, allowing movement of the microscope along the $\mathrm{x}, \mathrm{y}$, and $\mathrm{z}$ axes as well as the rotational and diagonal ones, and 2) a joystick at the level of the surgeon's mouth for adjustment of focus and zoom. The authors report on the initial experience with the use of the device at the Burdenko Neurosurgery Institute, where the senior author used it in approximately 600 procedures between 2006 and 2012. The surgeries ranged in difficulty and in duration (from 20 minutes to 7 hours, median 2.5 hours). Use of the Mari device resulted in increased accuracy of the surgical manipulations and a reduction in the duration of surgery.

(http://thejns.org/doi/abs/10.3171/2014.3.JNS12578)
\end{abstract}

$\begin{array}{lllll}\text { KEY WORDS } & \bullet & \text { operating microscope } \\ \text { surgery } & & \text { Mari device } & \bullet & \text { hands-free positioning }\end{array}$

A FTER the counter-balanced surgical microscope was introduced into surgical practice, the mouth switch was proposed for hands-free movement of the well-balanced microscope. ${ }^{2,3}$ Concurrently the foot control panel, allowing a surgeon to adjust optic parameters (focus and zoom), gained a wide acceptance. ${ }^{1}$ Using these 2 devices simultaneously lets a surgeon perform surgery without taking his or her hands away from the operative field.

Nevertheless, despite the advantages of the above-described devices, there are significant limitations to their use. The mouth switch is held in the surgeon's mouth during the whole procedure, and that may be inconvenient. Additionally, when turned on, the mouth switch releases the microscope's magnetic joints, permitting only translational movements (along the $\mathrm{x}, \mathrm{y}, \mathrm{z}$ axes) of the operating microscope, and these movements are not always sufficient to provide the required field of view. Rotational and diagonal movements of the operating microscope and adjustment of the optic parameters cannot be performed with this device.
The foot control panel only allows adjustment of focus and zoom. Moreover, changing the position around the operative field, especially when the surgeon operates in a standing position, causes additional difficulties in finding the foot control panel, which in turn requires additional effort and time and may be wearisome for the surgeon.

In light of all the above-mentioned disadvantages, we constructed a novel device (International Application No.: PCT/RU2007/000410) for hands-free utilization of the surgical microscope that eliminates the shortcomings described above.

\section{Device Description}

The Mari device (Fig. 1, Video 1) is provided for a multifunction counterweight-balanced surgical microscope and consists of a rectangular titanium holder with supportive plates; a frame that allows the device to be attached to the microscope eyepieces; a joystick and an electric switch for control of the microscope's functions; 


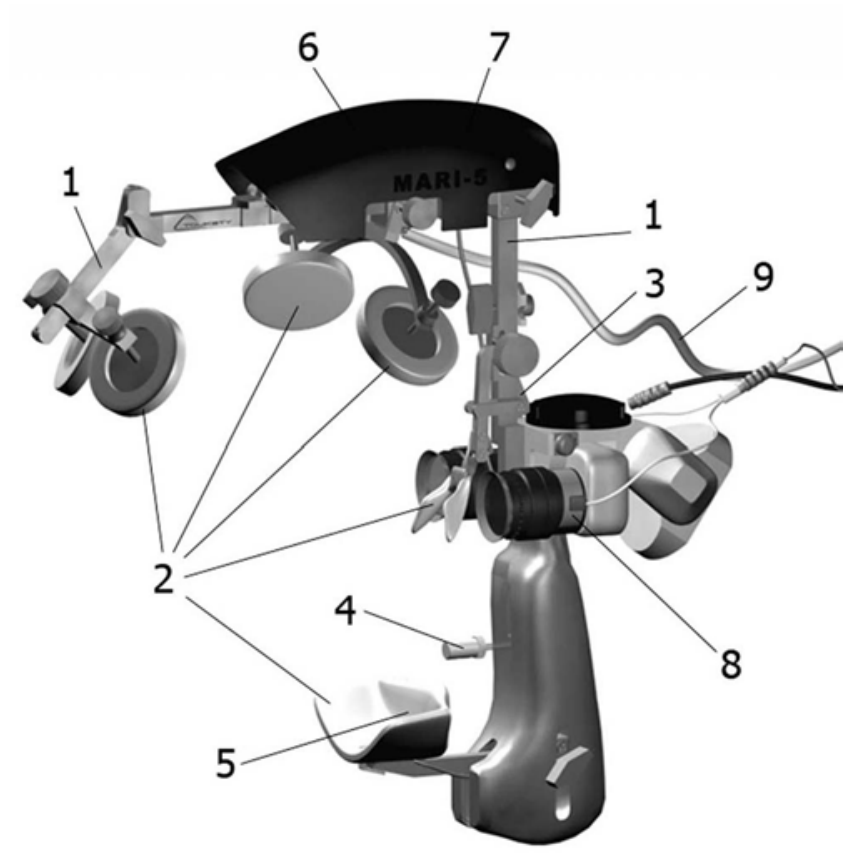

FIG. 1. Artist's representation of Mari device attached to the eyepieces of the microscope: a titanium holder (1); supportive plates (2) for parietooccipital area, forehead, bridge of the nose, and chin; the device frame (3); a joystick (4); an electric switch (5); electric drive (6) with locking mechanism and microprocessor (7) located under the hood; a heating system (8); and a multiwire cable (9).

a microprocessor; a small electric drive with a locking mechanism; an electric heating system; and a multiwire cable. A $12-\mathrm{V}$ transformer is used for power supply.

VIDEo 1. Video clip showing the design and application of the Mari device. Copyright David I. Pitskhelauri. Published with permission. Click here to view with Media Player. Click here to view with Quicktime.

The Mari device also comes with a pushing mechanism that allows the surgeon to press the release button located on the handgrip of the microscope (Fig. 2). The Mari device itself weighs $1100 \mathrm{~g}$ (without the pushing mechanism, cable, or transformer).

In all procedures, the surgeon used an NC4 or Pentero operating microscope (Carl Zeiss, Inc).

The holder with supportive plates allows interaction between the microscope and surgeon's head at the chin, bridge of the nose, and frontal and parietooccipital areas. The position of the supportive plates can be easily adjusted to the proportions of the surgeon's head. An electric switch installed in the chin support plate is connected to the pushing mechanism and allows the surgeon to activate the release of all the magnetic clutches of the microscope, which leads to moving the microscope as along the $\mathrm{x}, \mathrm{y}$, and $\mathrm{z}$ axes as well as the rotational and diagonal ones.

The Mari device is provided with a joystick (Fig. 1) fixed to the holder at the level of the surgeon's mouth. The signal transmission to the surgical microscope, including focus-up, focus-down, zoom-in, and zoom-out, can be regulated by the surgeon's lips. In addition, the joystick transmits the following control commands to the electric

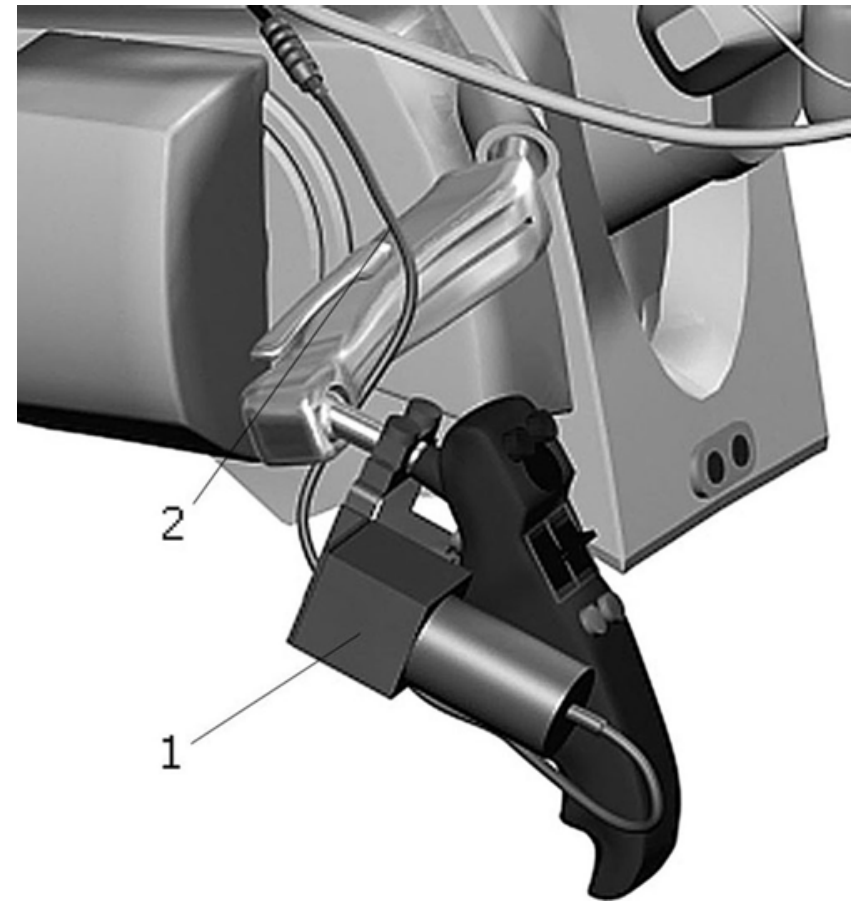

FIG. 2. Artist's representation of the pushing mechanism (1) fastened to the handgrip and its electric cable (2).

drive: lock the device and unlock the device. When the device is in the open position, double pressing the joystick forward leads to closing and locking the device and vice versa (double pressing the joystick forward in closed position opens the device, releasing the surgeon's head).

A multiwire cable (Fig. 1) provides a connection between the Mari device and the surgical microscope control system. The cable is connected to the microscope into the multiplug socket designed for a foot control panel.

\section{Mounting and Application of the Mari Device}

The device frame and heating system are attached to the binoculars. The heating system generates a temperature up to $30^{\circ} \mathrm{C}-35^{\circ} \mathrm{C}$ and prevents fogging of the surface of the eyepieces. The pushing mechanism is fastened to the left handgrip and is connected to the multiwire cable (Fig. 2). All the above-described components can be kept in place after the operation and will not cause any discomfort for the surgeon who operates without the device. After the surgical microscope is balanced and is covered with sterile drapes, the device is attached to the eyepieces of the microscope by the means of the frame using a single screw and then connected to the microscope control system by the multiwire cable. The surgeon takes the required position and by pressing the joystick forward turns the electric drive on; the back part of a holder (where the parietooccipital support plates are located) goes down and the device is locked (Video 1). The device is attached to the surgeon's head in such a way that the surgeon feels only a mild contact with the support plates without any excessive pressure on the head (Fig. 3). 


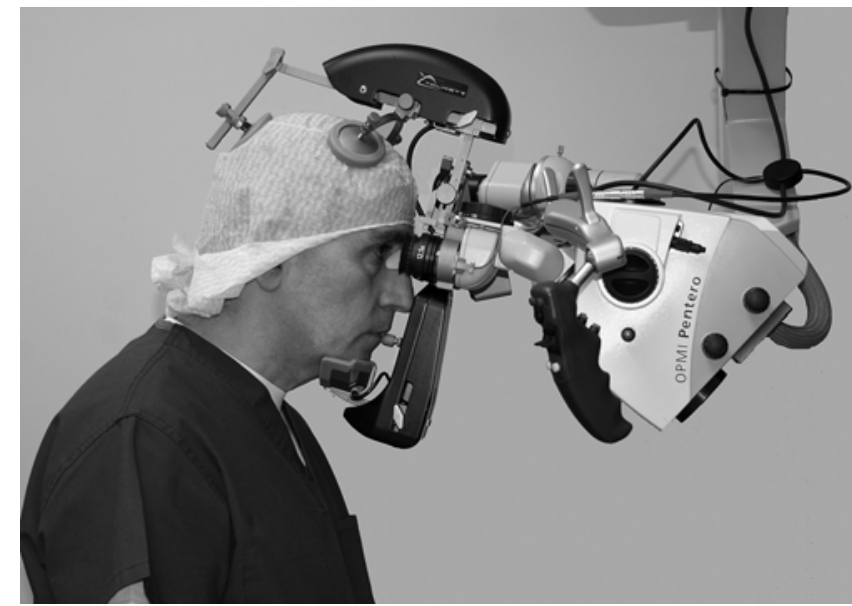

FIG. 3. Photograph showing surgeon in the required position for use of the Mari device. The device is locked and ready for use.

\section{Microscope Positioning}

When the surgeon opens his or her mouth and moves the chin slightly forward, the distance between the chin and the parietoocipital region of the head increases, leading to tight fixation of the head in the device between the supportive plates in the parietooccipital region, forehead, and the chin area. At the same time, opening the mouth causes the electrical switch (Fig. 1) to be pressed by the chin, which in its turn leads to release of all magnetic brakes of the surgical microscope. This maneuver permits the microscope to be moved by the surgeon's head through all planes of movement. It is important that the surgeon's eyes remain static relative to the microscope binoculars so that the view of the operative field remains consistent during microscope repositioning.

After the required position of the microscope is obtained, the surgeon closes his or her mouth, thereby releasing the electrical switch in the chin support plate, which in turn leads to simultaneous locking of all magnetic joints of the operating microscope. By closing the mouth the surgeon also reduces the pressure of the support plates on his or her head. Then all surgical manipulations are performed in the fixed position until the next movement is required.

The Mari device also allows for changing the angle between the microscope and the eyepieces in a hands-free way.

\section{Initial Clinical Experience with the Mari Device}

Between 2006 and 2012, approximately 600 operations have been performed with the Mari device at Burdenko Neurosurgery Institute by the first author and inventor of the device (D.I.P.). (See Addendum for updated information.) The Mari device has also been actively used by 2 residents in additional procedures under his supervision. The surgeries ranged in difficulty and in duration (from 20 minutes to 7 hours). Operations were performed with patients in supine (Fig. 4), sitting, prone, and lateral positions. The Mari device allowed the surgeon to move the operating microscope in all required directions

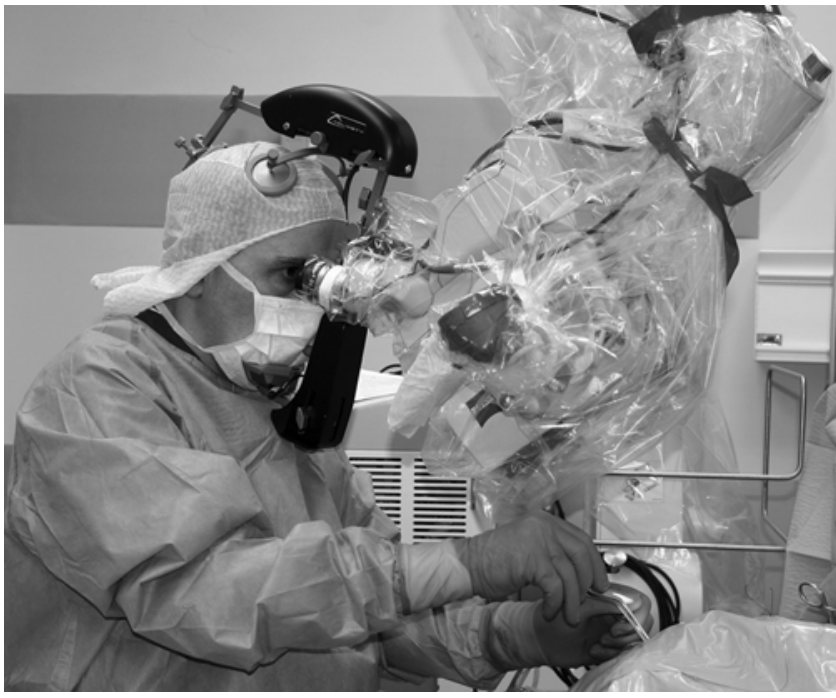

FIG. 4. Photograph showing the use of the Mari device during a surgical procedure.

around the operating field and to adjust focus and zoom without using his or her hands. This was especially helpful when the surgeon performed operations in a standing position and had to frequently change the angle of attack.

None of the cases was interrupted as a result of discomfort or malfunction of the Mari device, and there was no problem with the surgical microscope in any of the cases in which the Mari device was used.

It is important to note that mounting of Mari device is easy and safe for the microscope and does not require any changes to the microscope's hardware or software system. The device needs no sterilization, as there is no contact with sterile parts of the microscope.

In contrast to the mouth switch, the Mari device does not require the surgeon to continuously maintain a hold on parts of the device with his or her mouth. The surgeon's neck muscles are actively involved in the microscope positioning, so the static tension of these muscles significantly decreases during the operation. Moreover, when the operating microscope is in a fixed position, the surgeon can relax and lean against the frontal region plates of the device.

The Mari device allowed for increased accuracy of surgical manipulation and a reduction in the duration of surgery. It is particularly advantageous for operating on deep-seated brain lesions through a narrow corridor. The inventor of the device successfully applies it in all neurosurgical operations (without use of a brain retractor system), regardless of lesion location. The device can be applied not only for neurosurgical procedures but also in many different fields of microsurgery including cardiovascular surgery, where the microscope assistance is required.

The convenience of the Mari device is accompanied by some disadvantages as well. The surgeon's head is in a fixed position relative to the microscope, which to some extent restricts the free movement of the head. Nevertheless, we think that overall the advantages of the device outweigh its disadvantages. 


\section{Addenduum}

As of March 2014, the first author (D.I.P.) has used the device in over 1100 surgical procedures. The residents who initially worked with the device under his supervision have completed their residency training and are now actively using the device on their own. In addition, a senior surgeon at another leading Russian neurosurgical institute has performed more than 200 operations with the device.

\section{Acknowledgments}

We thank G. A. Inauri, A. A. Kirianov, and D. S. Shengelia for their generous support in the development of the device.

\section{Disclosure}

Dr. Pitskhelauri reports ownership in the Tolikety Co., Ltd., the company that manufactures the Mari device. Dr. Rojnin reports an employee relationship with Tolikety Co., Ltd.

Author contributions to the study and manuscript preparation include the following. Conception and design: Pitskhelauri. Acquisition of data: Pitskhelauri. Analysis and interpretation of data: Pitskhelauri, Shekutev, Rojnin. Drafting the article: Pitskhelauri, Samborsky. Critically revising the article: all authors. Reviewed submitted version of manuscript: all authors. Approved the final version of the manuscript on behalf of all authors: Pitskhelauri. Administrative/technical/material support: Pitskhelauri. Study supervision: Pitskhelauri.

\section{References}

1. Barraquer JI: The history of the microscope in ocular surgery. J Microsurg 1:288-299, 1980

2. Heller R, inventor; Contraves AG, assignee: Adjustable support for optical observation instrument. US patent 3,762,797. Oct. 2, 1973

3. Yaşargil MG, Vise WM, Bader DC: Technical adjuncts in neurosurgery. Surg Neurol 8:331-336, 1977

Manuscript submitted March 19, 2012.

Accepted March 6, 2014.

Please include this information when citing this paper: published online April 25, 2014; DOI: 10.3171/2014.3.JNS12578.

Supplemental online information:

Video: http://mfile.akamai.com/21490/wmv/digitalwbc.download. akamai.com/21492/wm.digitalsource-na-regional/jns12-578_video_ source_video_1.asx (Media Player).

http://mfile.akamai.com/21488/mov/digitalwbc.download .akamai. com/21492/qt.digitalsource-global/jns12-578_video_source_ video_1.mov (Quicktime).

Add̄ress correspondence to: David Pitskhelauri, M.D., Ph.D., Neurooncology, Burdenko Neurosurgery Institute, 4th TverskayaYamskaya Str. 16, Moscow 125047, Russia.email: davnsi@mail.ru. 